\title{
Sistemas construtivos para habitações sociais: uma revisão sistemática da literatura
}

O déficit habitacional brasileiro vem apresentando números cada vez maiores com o passar dos anos, chegando à marca recorde de 7,7 milhões em 2017. Esse problema social assola o país há mais de cem anos apesar dos diversos programas governamentais para combate-lo. A eficácia desses programas depende intrinsecamente dos sistemas construtivos disponíveis para que essas habitações sociais sejam construídas. Com essa perspectiva, esse artigo aborda o tema através de uma revisão sistemática da literatura buscando identificar os principais sistemas construtivos utilizados no país nos últimos 20 anos para a construção de habitações de interesse social, apontando suas especificações e debatendo sobre seus benefícios e desafios. Observou-se que a comunidade científica dispõe de bastante pesquisa em relação a vários modelos construtivos, onde entre eles se observa propostas inovadoras com grandes ganhos para a construção de habitações sociais atrelados a preservação do meio ambiente com controle de resíduos e racionamento de água, no entanto, a alvenaria convencional, que é utilizado desde a década de 1930, continua imperando como o sistema construtivo mais utilizado. Alternativas como o Light Steel Frame, Light Wood Frame, Concreto-PVC entre outros, se apresentam como possíveis substitutos, mas ainda precisam superar a barreira da baixa industrialização do país e da falta de especialização da mão de obra.

Palavras-chave: Sistemas Construtivos; Habitações Sociais; Revisão Sistemática.

\section{Constructive systems for social housing: a systematic review of the literature}

\begin{abstract}
The Brazilian housing deficit shows an increase in numbers over the last years, hitting the record mark of 7,7 millions in 2017. This social problem has been ravaging the country for over a hundred years despite numerous government programs to combat it. The efficacy of these programs depends intrinsically on the building systems available for the construction of social housings. With this perspective, this article approaches the theme through a systematic review of the literature, seeking to identify the main building systems utilized in the country for the construction of social housing, pointing to their specifications and debating about the benefits and challenges. It was observed that the scientific community has a whole lot of research in relation to various building models, and among them there are many who bring great gains to build socials houses in collusion with environmental preservation, controlling waste of materials and water, however, conventional masonry, which is utilized since 1930, continues to rule as the most utilized. Alternatives such as Light Steel Frame, Light Wood Frame, Concrete-PVC and many others have been shown as possible substitutes, but still faces the barrier of a country with low industrialization and lack of specialized labor.
\end{abstract}

Keywords: Constructive Systems; Social Housing; Systematic Review.

Topic: Construções e Arquitetura Sustentáveis

Reviewed anonymously in the process of blind peer.
Received: 04/03/2021

Approved: 23/03/2021
Luís Felipe Sousa (iD)

Universidade Federal do Maranhão, Brasil http://lattes.cnpq.br/7087025472783068 http://orcid.org/0000-0003-4621-5827 luiss.fs@hotmail.com

Maria Luiza Lopes de Oliveira Santos (iD Universidade Federal do Maranhão, Brasil $\underline{\text { http://lattes.cnpq.br/7052771233872451 }}$ http://orcid.org/0000-0001-8373-850X mllo.santos@ufma.br

\section{Referencing this:}

SOUSA, L. F.; SANTOS, M. L. L. O.. Sistemas construtivos para habitações sociais: uma revisão sistemática da literatura. Revista Ibero Americana de Ciências Ambientais, v.12, n.3, p.194-206, 2021. DOI: http://doi.org/10.6008/CBPC2179-6858.2021.003.0018 


\section{INTRODUÇÃO}

Segundo um estudo da Fundação Getúlio Vargas (FGV, 2018), o déficit habitacional no Brasil chegou a sua maior marca da série histórica com 7,77 milhões de unidades habitacionais no ano de 2017 . Onde, 42\% desse número é composto por famílias que moram de aluguel, 41\% por coabitação (várias famílias vivendo sob o mesmo teto), e cerca de $17 \%$ se refere às habitações precárias, localizadas em parte nas favelas e outras habitações irregulares.

Para responder a essa mazela social, diversos governos brasileiros já implementaram programas que tinham como objetivo fomentar a construção e o financiamento de habitações populares. Podemos citar como os principais: os Institutos de Auxilio e Pensão (IAPs) junto com a Fundação Casa Popular, que duraram entre 1937 e 1964, o Banco Nacional de Habitação (BNH) juntamente com o Sistema Financeiro de Habitação (SFH), com duração entre 1964 até 1986, e, por último, o Programa Minha Casa Minha Vida (PMCMV), criado em 2009 e vigente no país até hoje (RAMOS et al., 2016).

Para atingir as metas estabelecidas em cada período em que os programas foram implementados, era necessário um investimento pesado em inovações tecnológicas para o desenvolvimento de novos sistemas construtivos que proporcionassem à indústria da construção civil a capacidade de criar unidades habitacionais sustentáveis, tanto do ponto de vista econômico quanto ambiental (RAMOS et al., 2016).

Hoje, no Brasil, podemos encontrar diversos sistemas construtivos sendo utilizados, desenvolvidos e aprimorados, como por exemplo, os Sistemas Light Wood Frames, Concreto-PVC, Placas de Concreto, Steel Frame, Alvenaria Convencional e Alvenaria Estrutural.

Alguns desses sistemas construtivos já estão estabelecidos no mercado há décadas, e, por vezes, geraram debates a respeito de sua eficácia. Outros entraram como uma forma de dar mais opções para as diferentes regiões do Brasil e suas diversas fontes de matérias-primas, além de oferecer novos métodos para construções mais rápidas, baratas e sustentáveis (GARCIA et al., 2013).

Este trabalho tem como objetivo realizar uma Revisão Sistemática da Literatura (RSL) a respeito dos sistemas construtivos utilizados na construção de habitações populares nos últimos 20 anos no Brasil. Devido à vasta quantidade de sistemas, essa RSL tem a intenção de compilar artigos publicados que abordem o tema de forma abrangente e enriqueçam o debate a respeito das melhores alternativas na construção civil para o combate do déficit habitacional. Para isso, deve-se analisar de forma objetiva as opções no mercado brasileiro, suas características, tendências e problemas.

A estrutura do trabalho se inicia com a apresentação da metodologia empregada na revisão sistemática, com as bases de dados utilizadas, as palavras-chave, os parâmetros de filtragem e o fluxo de análise e seleção dos artigos. Em seguida, são apresentados os resultados da pesquisa, incluindo os sistemas propostos pelos artigos analisados, além de um debate sobre os principais aspectos dos métodos construtivos expostos. Nas considerações finais são apresentadas as principais contribuições dos estudos, os limites encontrados e as perspectivas para pesquisas futuras. 


\section{METODOLOGIA}

A Revisão Sistemática da Literatura (RSL) representa uma modalidade de pesquisa que tem como objetivo realizar a ampla análise de uma vasta quantidade de documentos (artigos, monografias, teses etc.) encontrados na literatura que tratem de um determinado tema. Esse tipo de pesquisa deve expor de forma lógica e pragmática o que se foi observado, possibilitando sua reprodução por outros pesquisadores ao apresentar a base de dados aplicada, os critérios de busca, eliminação e exclusão de artigos, além do seu processo de análise (GALVÃO et al., 2019).

A nossa RSL foi elaborada através de um protocolo de caráter misto baseado em Galvão et al. (2019). Ainda segundo Galvão et al. (2019), "revisão de literatura sistemática de caráter misto [...] aquela que identifica, seleciona, avalia e sintetiza simultaneamente estudos qualitativos, estudos quantitativos e estudos mistos".

\section{Bases de dados}

As bases de dados selecionadas para a pesquisa dos artigos foram a Scielo e o Google Acadêmico. A seleção decorreu da prevalência em se buscar utilizar trabalhos produzidos no Brasil e escritos em língua portuguesa. Além disso, essas bases de dados disponibilizam ótimos mecanismos de filtragem que permitem uma maior eficácia no retorno das buscas.

\section{Estratégias de busca}

Para efetivar a busca foram selecionadas as seguintes palavras-chave: 'Sistemas Construtivos', 'Habitação', 'Habitações Sociais' e 'Habitação Popular'. Em ambas as plataformas, se utilizou a forma de busca avançada disponibilizada pelos sítios para que se obtivesse o retorno de resultados mais precisos. Utilizouse também o operador booleano 'AND' para criar intersecção nas pesquisas, e, assim, limitar ainda mais os resultados retornados.

A busca foi realizada em três etapas. Em cada uma, utilizaram-se as palavras-chave citadas anteriormente, juntamente com a aplicação do operador booleano. As pesquisas selecionadas foram publicações entre os anos 2000 e 2020.

A escolha dos artigos foi realizada em duas etapas. Na primeira, foram selecionados os artigos apenas pela leitura de seus títulos. Na segunda, foi realizada a leitura dos resumos de cada artigo selecionado, para, assim, determinar se teriam conteúdo relevante para ser incluídos na RSL.

O critério para inclusão na RSL foi: estudos que tratam de sistemas construtivos utilizados na construção de habitações de interesse popular nos últimos 20 anos no Brasil. Já os critérios de exclusão foram: trabalhos repetidos, trabalhos que não condizem com o tema, trabalhos sem acesso livre, trabalhos sem resumo, artigos com temática pouco abrangente, outros tipos de trabalhos acadêmicos (monografia, tese, dissertação; etc.). O processo de busca e seleção está explicitado a seguir. 
Scielo

Para essa busca se utilizou a ferramenta 'pesquisa avançada' com os filtros: Coleção: Brasil; Idioma: Português; Tipo de Literatura: Artigos. A sequência de busca e resultados estão na tabela 1 e na figura 1. Utilizando o diagrama de fluxo de seleção PRISMA (LIBERATTI et al., 2015) figura 1.

Tabela 1: Estratégia de busca.

\begin{tabular}{lll}
\hline Pesquisa & Palavras-chave & Resultados \\
\hline $1 \underline{a}$ & "Sistemas Construtivos" & 40 \\
\hline $2 \underline{a}$ & "Sistemas Construtivos" AND “Habitação" & 3 \\
\hline aa & "Sistemas Construtivos" AND “Habitações Sociais" & 0 \\
\hline $4 \underline{a}$ & "Sistemas Construtivos" AND "Habitação popular" & 0 \\
\hline
\end{tabular}

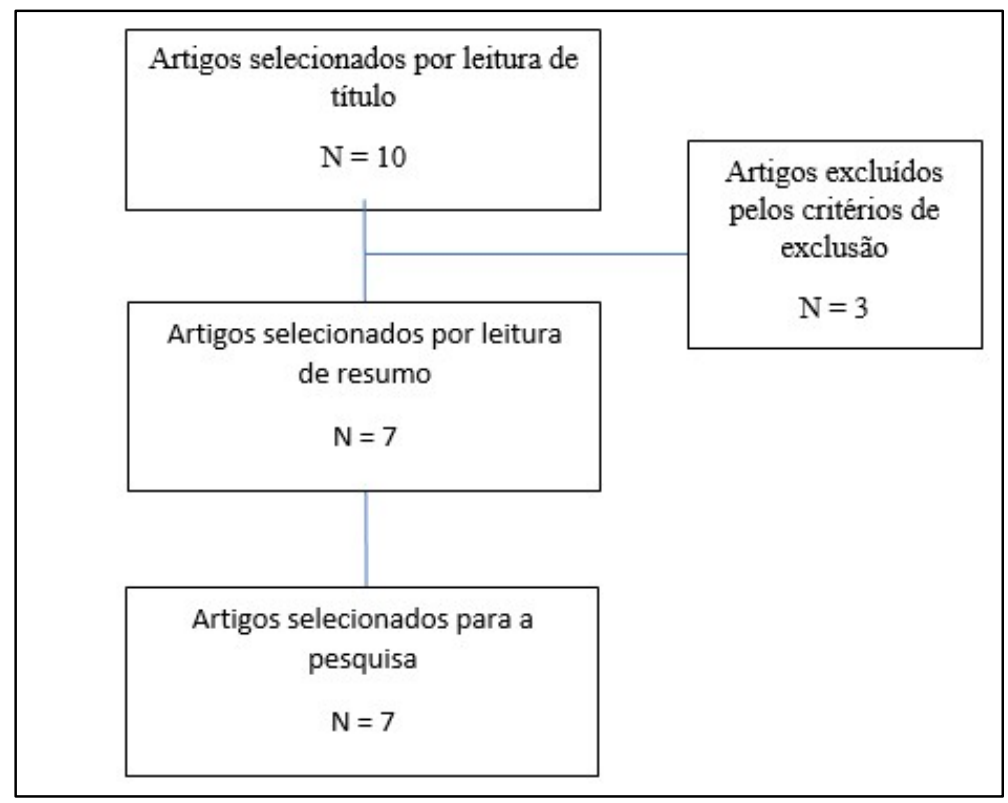

Figura 1: Fluxograma PRISMA de seleção de artigos.

\section{Google Acadêmico}

Para essa busca se utilizou a ferramenta 'pesquisa avançada' com os filtros: pesquisar páginas em português; classificar por relevância; período específico entre 2000 - 2020; localizar palavras-chave em qualquer lugar do artigo.

Pelo grande número de resultados que a plataforma retorna, se fez a análise apenas das 10 primeiras páginas e, uma vez que cada página apresenta 10 artigos, foram observados 100 artigos por pesquisa. Como os resultados são ranqueados por relevância, pode se concluir que esses são os artigos mais relevantes, ou seja, com mais citações em trabalhos acadêmicos. A sequência da pesquisa e os resultados são apresentados na tabela 2 e no fluxograma da figura 2. Utilizando o diagrama de fluxo de seleção PRISMA (LIBERATTI et al., 2015) na figura 2.

Tabela 2: Estratégia de busca.

\begin{tabular}{lll}
\hline Pesquisa & Palavras-chave & Resultados \\
\hline $1 \underline{\underline{a}}$ & "Sistemas Construtivos" & 12.300 \\
\hline $2 \underline{\underline{a}}$ & "Sistemas Construtivos" AND “Habitação" & 6420 \\
\hline $3 \underline{\underline{a}}$ & "Sistemas Construtivos" AND “Habitações Sociais" & 375 \\
\hline $4 \underline{\underline{a}}$ & "Sistemas Construtivos" AND "Habitação popular" & 110 \\
\hline
\end{tabular}




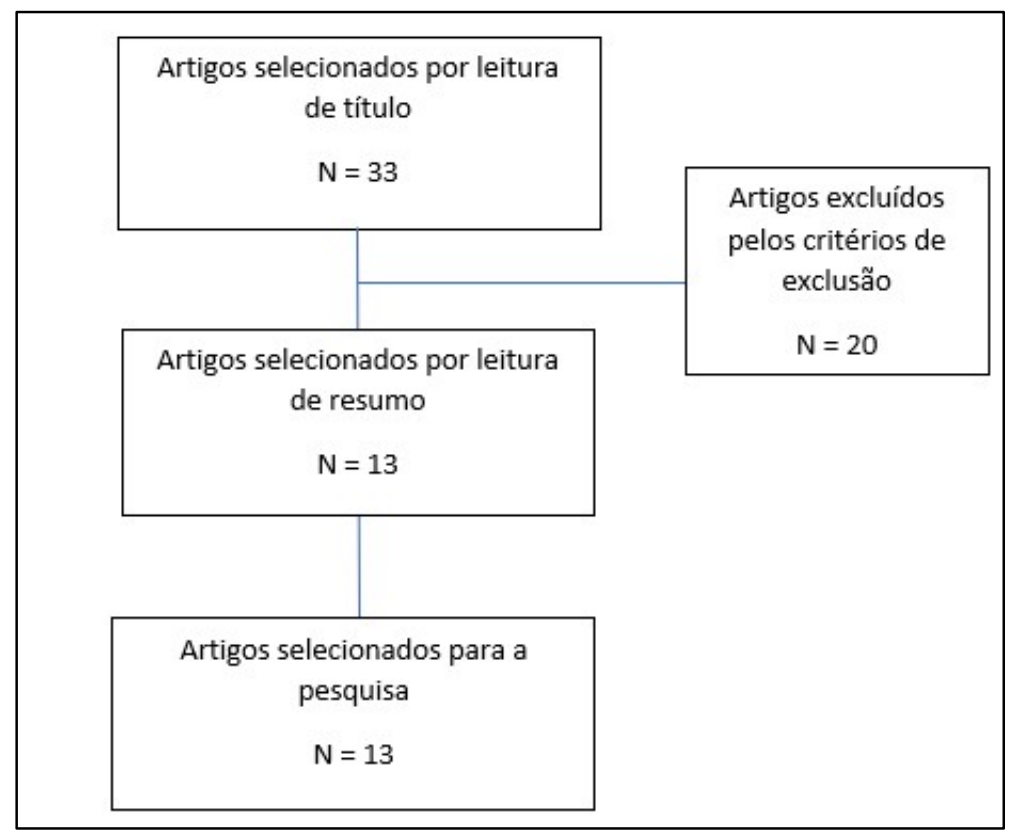

Figura 2: Fluxograma PRISMA de seleção de artigos.

No total, foram selecionados 20 artigos para a realização da revisão sistemática, todos eles seguindo os critérios de inclusão citados anteriormente. Estes artigos estão listados na tabela 3 a seguir.

Tabela 3: Artigos selecionados para a RSL.

\begin{tabular}{|c|c|c|}
\hline Título & Ano & Autores \\
\hline Utilização da Madeira em Construções Rurais & 2000 & Calil Júnior et al. \\
\hline $\begin{array}{l}\text { A utilização de novos sistemas construtivos para a redução no uso de insumos nos canteiros de } \\
\text { obras: Light Steel Framing }\end{array}$ & 2017 & Olivieri et al. \\
\hline $\begin{array}{l}\text { Sistemas Construtivos Inovadores no Contexto do SiNAT: Normativas, Produção e Aplicações de } \\
\text { Painéis de Vedação }\end{array}$ & 2017 & Mendes et al. \\
\hline $\begin{array}{l}\text { Diretrizes de projeto para a redução de perdas na produção de Habitações de Interesse Social } \\
\text { customizadas com painéis pré-fabricados em sistemas de construção a seco }\end{array}$ & 2018 & Nogueira et al. \\
\hline Panorama do sistema construtivo Light Wood Frame no Brasil & 2018 & Sotsek et al. \\
\hline $\begin{array}{l}\text { Inserção e financiamento do sistema Wood Frame no programa habitacional minha casa minha } \\
\text { vida }\end{array}$ & 2014 & Espindola et al. \\
\hline $\begin{array}{l}\text { Diretrizes para planejar e controlar o processo de montagem de sistemas construtivos pré- } \\
\text { fabricados de aço }\end{array}$ & 2020 & Fabro et al. \\
\hline Vantagens ambientais do sistema construtivo Light Steel Framing no segmento da construção civil & 2019 & Guimarães et al. \\
\hline $\begin{array}{l}\text { Comparativo econômico da aplicação do Sistema Light Steel Framing em habitação de interesse } \\
\text { social }\end{array}$ & 2012 & Bernades et al. \\
\hline Estudo comparativo entre o sistema construtivo a seco (Steel Frame) e alvenaria comum & 2019 & Costa et al. \\
\hline Light Steel Frame: construção industrializada a seco para habitação popular - práticas sustentáveis & 2013 & Gomes et al. \\
\hline $\begin{array}{l}\text { Análise comparativa dos sistemas construtivos alvenaria convencional e light steel framing: um } \\
\text { estudo de caso em residência unifamiliar em Teófilo Otoni, MG }\end{array}$ & 2019 & Salomão et al. \\
\hline $\begin{array}{l}\text { Diretrizes para a definição de lotes de montagem de sistemas pré-fabricados de concreto do tipo } \\
\text { engineer-to-order }\end{array}$ & 2020 & Reck et al. \\
\hline $\begin{array}{l}\text { Aplicação de processo de racionalização utilizando blocos de concreto e avaliação de desempenho } \\
\text { térmico-estrutural de habitação de interesse social construída em Maceió }\end{array}$ & 2005 & Farias et al. \\
\hline $\begin{array}{l}\text { Desempenho estrutural de protótipo de alvenaria construída com blocos de terra crua } \\
\text { estabilizada }\end{array}$ & 2011 & Melo et al. \\
\hline $\begin{array}{l}\text { Sistemas construtivos industrializados para habitação social: análise do container como uma nova } \\
\text { alternativa }\end{array}$ & 2019 & Souza et al. \\
\hline Análise de diferentes tipologias de construção em concreto e PVC & 2014 & Brandão et al. \\
\hline Disposições técnicas e diretrizes para projeto de habitações sociais evolutivas & 2011 & Brandão \\
\hline Desenvolvimento de Alternativas Sustentáveis Para Habitação de Baixa Renda & 2008 & Carvalho et al. \\
\hline
\end{tabular}

\section{Análise de conteúdo}

A leitura e análise dos artigos selecionados foram feitas por meio de uma ficha de leitura, pela qual 
se buscou identificar a metodologia empregada em cada trabalho, os benefícios que o estudo traz para o campo e os principais desafios observados na elaboração da pesquisa. Ademais, se analisaram os principais dados fornecidos, a fim de se estabelecer convergências entre os sistemas construtivos abordados, tão como identificar e expor similaridades nos temas que circundam o debate acadêmico.

\section{RESULTADOS E DISCUSSÃO}

Através da análise dos artigos, se observou que os autores trabalharam de duas formas. Introdutória, onde se apresentou um sistema construtivo e se desenvolveu o trabalho em cima das suas aplicações em alguma habitação construída no país nos últimos 20 anos, analisando suas vantagens e desvantagens. E de forma comparativa, onde se analisava dois ou mais sistemas construtivos, traçando comparações qualitativas e quantitativa entre os mesmos.

Por vezes, o mesmo sistema foi tratado em artigos diferentes, o que mostra seu grau de relevância dentro do debate acadêmico a respeito dos diversos sistemas utilizados para a construção de habitações de interesse social. Em vista disso, no gráfico 1 estão apresentados os sistemas construtivos analisados nessa RSL e a porcentagem em que estes foram citados nos artigos analisados.

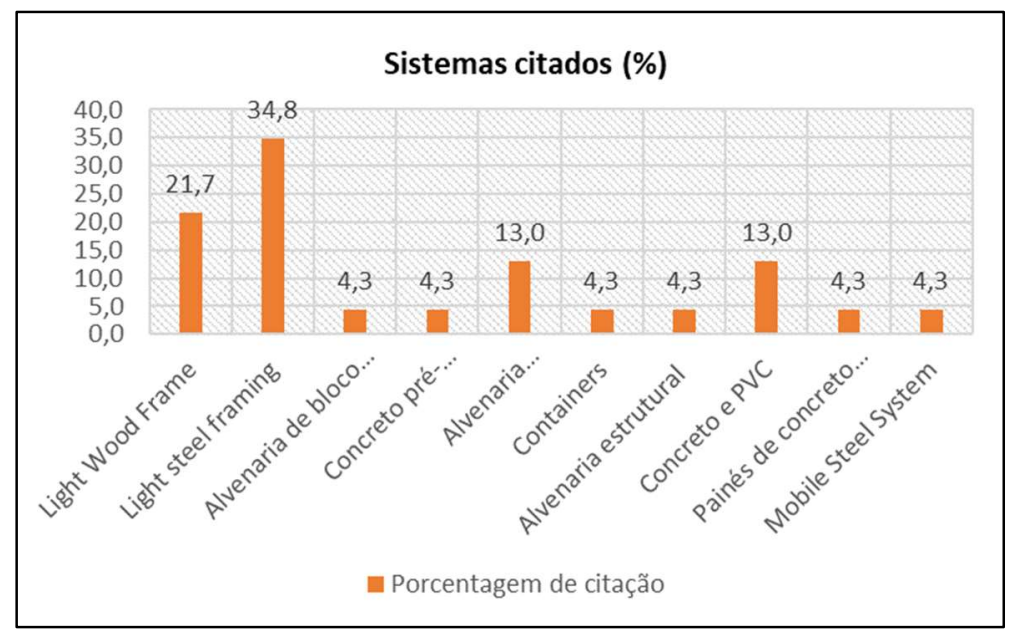

Gráfico 1: Sistemas construtivos.

Como já mencionado anteriormente, os autores empregaram diferentes metodologias para descrever seus respectivos sistemas construtivos de estudo, onde se observa seus benefícios e desafios para divulgação e implementação no mercado nacional. Abaixo seguem os sistemas encontrados na pesquisa com sua síntese de acordo com os artigos analisados:

Light Wood Frame (LWF): o sistema é citado por: Mendes et al. (2017), Calil Júnior et al. (2000), Nogueira et al. (2018), Sotsek et al. (2018) e Espindola et al. (2014). Podemos defini-lo como composto por peças leves de madeira maciça para fins estruturais e com vedação feita por chapas delgadas. Possui diretriz registrada no SINAT de no 005, que define os parâmetros para seu uso nas construções de habitações sociais.

Light Steel Frame (LSF): consiste em um sistema que utiliza perfis esbeltos de aço zincado formados a frio para a construção estrutural e se faz a vedação com painéis ou placas de origem industrializada que pode ser de aço, madeira, concreto ou outro material de boa resistência. Para construções recomenda-se 
seguir a diretriz no 003 do SINAT. Esse sistema é citado por Mendes et al. (2017), Olivieri et al. (2017), Fabro et al. (2020), Guimarães et al. (2019), Bernardes et al. (2012), Costa et al. (2019), Gomes et al. (2013) e Salomão et al. (2019).

Alvenaria Convencional: definido por um sistema composto por fundação (rasa ou profunda). Tratase de uma estrutura feita em concreto armado moldado in loco e vedações verticais construídas em blocos cerâmicos assentados por argamassa (cimentícia ou de outro material). É o sistema construtivo mais utilizado no Brasil. O começo de sua utilização de 1930 e é considerado pelos pesquisadores o sistema a se substituir, tendo em vista que boa parte dos quadros comparativos são feitos para demonstrar a ineficiência da alvenaria convencional em relação aos novos sistemas. O sistema é citado por Bernardes et al. (2012), Costa (2019), Salomão et al. (2019), Olivieri et al. (2017).

Concreto Pré-fabricado: se trata de um sistema composto por estrutura de concreto moldada em fábrica (fora do local de uso), o que acarreta em uma estrutura com maior controle tecnológico e de qualidade. É citado por Reck et al. (2020).

Alvenaria Estrutural: sistema caracterizado por ter as paredes como elementos não apenas de vedação, mas também exercendo funções estruturais, de isolamento térmico, acústico e proteção contra incêndios. Os principais materiais utilizados são os blocos (cerâmicos ou de concreto), argamassa, graute e aço. É citado por Farias et al. (2005).

Alvenaria de Blocos de Terra Crua Estabilizada: se assemelha à alvenaria estrutural, mas suas construções se limitam a habitações de pequeno porte. Os blocos são confeccionados com terra crua prensada em máquina manual ou mecânica, onde com a pressão o material é compactado e moldado de acordo com o formato estabelecido. É um modelo baseado nos tijolos de solo cimento. Esse sistema é citado por Melo et al. (2011).

Concreto-PVC: é composto por placas de PVC vazadas que são preenchidas com concreto autoadensável e armadura de aço após sua montagem na obra. De origem canadense, esse sistema possui um alto grau de industrialização, além de ser caracterizado como modular, ou seja, as paredes de PVC são fabricadas com encaixe macho-fêmea, o que acelera sua montagem in loco. Citam esse sistema construtivo Souza et al. (2019), Mendes et al. (2017) e Brandão et al. (2014).

Containers: são grandes caixas metálicas que possuem em média $28 \mathrm{~m}^{2}$ de área e $2,50 \mathrm{~m}$ de altura. São muito utilizadas na indústria náutica e ferroviária para o transporte de cargas, mas vêm ocupando o setor da construção civil como nova alternativa construtiva. Primeiramente utilizado para empreendimentos comerciais, com tempo, habitações de interesse sociais também se tornaram uma opção para se utilizar esse sistema. Para se usar de forma excepcional é necessária a utilização em conjunto de outros materiais, como revestimentos em áreas molhadas, poliestireno para resistência térmica e placas de PVC para acabamento. Souza et al. (2019) citam esse tipo de sistema construtivo.

Mobile Steel System (MSS): é formado por sistemas de painéis-sanduíche de aço galvanizado com seu interior preenchido com poliuretano. Sua montagem é feita através dos encaixes no formato machofêmea e cabos de aço para amarração. A fundação geralmente é do tipo radier, já que o sistema não possui 
um grande peso próprio, além de não ser feito para grandes gabaritos. Este é citado por Souza et al. (2019).

Painéis de Concreto in Loco: consiste em um sistema formado por paredes e lajes de concreto armado que são moldados no local da obra utilizando-se de fôrmas removíveis pré-fabricadas. As fôrmas precisam ser confeccionadas já com os vãos de portas e janelas de acordo com o projeto, mantendo-se na obra uma rotatividade constante para construir os elementos de forma mais eficaz, além da necessidade de se utilizar o concreto autoadensável. No SINAT encontra-se a diretriz no 001 que estabelece o uso deste sistema em habitações sociais. Mendes et al. (2017) citam esse tipo de sistema construtivo.

Destaca-se a utilização do sistema Light Steel Frame (LSF) no quesito sustentabilidade, onde autores que trataram do assunto, como Olivieri et al. (2017), Guimarães et al. (2019), Bernardes et al. (2012) e Salomão et al. (2019), argumentam que, por ser a seco, o sistema diminui drasticamente o uso de água nas construções. Em comparação ao sistema de alvenaria convencional, há uma redução de 93,5\% do volume de água utilizado na construção, onde esse consumo deriva da fabricação da argamassa cimentícia, do concreto e do uso diário por parte dos trabalhadores (OLIVIERI et al., 2017).

Outro fator importante está relacionado ao fato do LSF ser feito de aço zincado, onde todas as suas peças são facilmente recicláveis, devido à natureza maleável do material que ao ser exposto a altas temperaturas pode ser remoldado para outras finalidades. Em relação a isso, Olivieri et al. (2017) argumenta que:

O sistema LSF pode representar uma redução significativa de $86,7 \%$ na geração de resíduos da construção quando comparado ao sistema tradicional. Destaca-se também o tipo de resíduo gerado, uma vez que o resíduo de LSF é pertencente, quase em sua totalidade, à Classe B (Conama no 307) (CONSELHO..., 2002), o que garante seu retorno na cadeia produtiva como um produto altamente reciclável por outras indústrias do setor da construção. Já o resíduo da construção gerado pelo método tradicional é pertencente à Classe A (Conama no 307) (CONSELHO..., 2002), que prevê sua maior aplicação como agregado reciclado em argamassas e concretos não estruturais. Esse tipo de reutilização e reciclagem necessita de processos de segregação, britagem e peneiramento antes de retornar ao processo produtivo novamente. Portanto, devem-se destacar as diferenças apresentadas na reutilização, reciclagem, destinação e disposição dos diferentes resíduos gerados.

Em relação aos custos, se observa que o sistema LSF apresenta um valor relativamente mais alto que os sistemas tradicionais no mercado brasileiro. Isso se dá pela falta de demanda, a baixa industrialização do país para produzir os materiais necessários para uso do sistema e a falta de conhecimento técnico da mão de obra (BERNARDES et al., 2012).

Em um estudo de campo, Bernardes et al. (2012) afirma que "[...] o LSF apresentou valores finais $23,15 \%$ maiores que o sistema convencional, em virtude de ser uma tecnologia relativamente nova na região". O que evidencia além dos pontos ditos anteriormente o fator regional na influência dos custos da implementação do sistema. As regiões com maior número de fábricas de aço terão maior vantagem sob as mais carentes deste serviço (GOMES et al., 2013).

Em contraponto, esse preço elevado é apenas observado quando se compara o sistema LSF com o convencional olhando apenas para os materiais. Quando analisamos por outros campos que envolvem a construção do empreendimento, pode-se obter ganhos significativos com a utilização do sistema, como por 
exemplo, em relação a alvenaria convencional a LSF consome 62,5\% menos mão de obra, reduz em $86,7 \%$ a massa de resíduos produzidos, e tem prazo de conclusão de obra 3 vezes mais rápida (GUIMARÃES et al., 2019).

Outro ponto a ser levantado sobre o sistema é a necessidade de um polo industrial forte voltado para atender esse novo mercado. Isso se dá, pois, sistemas como o LSF são extremamente dependentes de planejamentos rigorosos para que tenha sua implementação correta. O controle do transporte dos materiais, desde a chegada na obra, considerando também o armazenamento e a montagem, precisam ser feitos com a maior precisão possível e dispensam improvisos que são geralmente praticados na construção de alvenaria convencional (GOMES et al., 2013).

O sistema Light Wood Frame (LWF) por ser um modelo de construção a seco também apresenta vantagens equiparáveis ao LSF, por não utilizar concreto como base principal da construção (salvo pelas fundações, geralmente rasas) além de gerar grande economia de água também reduz o consumo do cimento, material responsável por grandes emissões de $\mathrm{CO}_{2}$ durante sua manufatura. Em relação a isto, Sotsek et al. (2018) argumentam que:

[...] aumentar o uso da madeira na construção ajudaria a atingir os objetivos de desenvolvimento sustentável de forma mundial. [...] a substituição do material de madeira por outros materiais de construção, como concreto e aço, pode reduzir as emissões líquidas de $\mathrm{CO}_{2}$ e o uso de energia primária, visto que [...], o setor de construção civil é um dos maiores consumidores desses insumos no mundo.

No imaginário de muitas pessoas existe certo receio ao utilizar madeira na construção de habitações no Brasil. Os principais argumentos em relação a isso é a ideia de que a madeira é um material muito frágil para resistir à cargas, ao fogo, degrada muito fácil, não fornece proteção o bastante contra intempéries, conforto acústico, dentre outros (CALIL JÚNIOR et al., 2000).

De forma empírica, através de anos de estudos, esses conceitos prévios a respeito do material por muitas vezes foram refutados. Na tabela 4 estão alguns dados encontrados em Calil Júnior et al. (2000) que comparam a madeira a outros materiais que se utiliza bastante nas construções brasileiras.

Tabela 4: Comparação entre materiais.

\begin{tabular}{llll}
\hline Material & Aço & Concreto & Madeira Conífera/Dicotiledônea \\
\hline Densidade $\left(\mathrm{KN} / \mathrm{m}^{3}\right)$ & 78 & 24 & $6 / 9$ \\
\hline Energia para produção $\left(\mathrm{MJ} / \mathrm{m}^{3}\right)$ & 1920 & 234000 & $600 / 630$ \\
\hline Resistência $(\mathrm{MPa})$ & 250 & 20 & $5000 / 9000$ \\
\hline Módulo de Elasticidade (MPa) & 20000 & 210000 & $10000 / 25000$ \\
\hline
\end{tabular}

Fonte: Calil Júnior et al. (2000)

Os números mostram como a madeira é uma forte competidora com o aço e o concreto como material construtivo. Com densidade tão baixa em relação aos outros materiais o processo de montagem se torna muito mais simples e, por consequência, menos oneroso. Outro ponto importante a se notar é a grande diferença entre os materiais em relação à energia de produção. Como a maioria da energia no Brasil é produzida por hidrelétricas ou termoelétricas, um material que necessita de pouca energia para ser produzido se torna muito mais amigável ao meio ambiente, além de refletir de forma positiva no valor final do produto. 
Em relação à resistência ao fogo, a madeira contraria o pensamento natural que uma pessoa leiga possa ter e apresenta desempenho aceitável, até melhor que materiais como o aço. Isso se dá, pois, quando a madeira é exposta a altas temperaturas é formada uma camada de carvão na parte exterior da peça que, por sua vez, protege seu interior, evitando que a deformação aconteça de forma excessiva, além disso a madeira não é um material com boa condutibilidade de calor (CALIL JÚNIOR et al., 2000).

Algo que preocupa muitos estudiosos do sistema é a forma em que a matéria-prima seria extraída, tendo em vista o histórico brasileiro de extração criminosa de madeira em áreas protegidas. Se propõem em Sotsek et al. (2018) que a madeira utilizada para a construção de habitações em LWF seja apenas de áreas próprias para o plantio de espécies direcionadas ao uso, como o eucalipto, e que funcione de forma cíclica onde há a extração e o replantio feito de forma que não desestabilize o ecossistema.

Os custos da implementação desse sistema podem variar de acordo com os pontos traçados na discussão sobre o LSF, já que no país não há uma estruturação comprometida com a manufatura dos insumos necessários e mão de obra nacional não possui qualificação adequada para o tratamento deste modelo de forma apropriada.

O conjunto habitacional Haragano foi o primeiro projeto de habitação social construído no país com LWF. Localizado em Pelotas no Rio Grande do Sul, o empreendimento construiu, em um lote com área de 3,98 hectares, 280 unidades habitacionais com $45 \mathrm{~m}^{2}$, distribuídas entre sobrados geminados e casas térreas. A construção foi feita através do PMCMV seguindo as diretrizes estabelecidas pelo SINAT para construção.

Sistemas construtivos como a alvenaria convencional, a alvenaria estrutural e o concreto prémoldado são os mais estabelecidos no mercado brasileiro. Isso advém do histórico desses modelos no contexto histórico do país.

A década entre os anos de 1930 e 1940 foi decisiva para o estabelecimento da construção civil como indústria no Brasil. O desenvolvimento e a utilização do concreto armado como principal sistema de estrutura teve papel categórico no setor.

O concreto está no cerne da consolidação de um dos poucos sistemas tecnológicos genuinamente desenvolvidos no Brasil e é peça chave na estruturação do campo da arquitetura e da engenharia e de todas as práticas que ele põe em jogo. A construção civil brasileira está estruturada em torno do sistema construtivo do concreto armado.

A partir dos anos 1970 se iniciou o desenvolvimento e implementação do concreto pré-moldado e da alvenaria estrutural. Esse avanço veio através de programas governamentais ligados ao $\mathrm{BNH}$, que buscavam impulsionar a construção de habitações de forma mais rápida.

Por esse contexto é possível encontrar em todas as regiões do país toda a rede de alimentação desses sistemas. Na maioria das grandes cidades é possível encontrar com facilidade cimento, areia, brita, blocos cerâmicos, blocos de concreto e fábricas de concreto pré-moldado. Além disso, a grande maioria da mão de obra se especializou na execução de obras utilizando tais sistemas o que a torna mais barata pela sua alta disponibilidade.

Em contrapartida, como comentado anteriormente, a busca por novos sistemas se torna cada vez mais requisitada pela comunidade científica devido ao grande impacto ambiental que estes sistemas causam, 
tanto pela quantidade de resíduo produzido como pelo uso de materiais nocivos para o planeta.

Uma alternativa para o sistema de alvenaria estrutural seria a utilização de blocos reciclados como os apresentados por Farias et al. (2005) que são produzidos utilizando resíduos da construção e demolição de empreendimentos.

Os sistemas Concreto-PVC, Painéis de concreto moldados in loco e MSS se assemelham pelo alto grau de industrialização e forma de construção. Todos prezam pelo sistema de modulação, onde as fôrmas da construção já são estabelecidas com as medidas necessárias, os vãos e os espaços determinados para comportar os sistemas hidrossanitários e elétricos.

No entanto, os sistemas enfrentam problemas na viabilidade de custo em comparação à alvenaria convencional, e, até mesmo, aos outros sistemas apresentados nesta RSL. Em relação a isso Brandão et al., (2014) argumentam:

[...] a utilização do sistema construtivo em Concreto e PVC em substituição ao sistema tradicional em alvenaria de blocos cerâmicos proporciona um ganho significativo de área em projeto. Porém o custo de construção pode ser um empecilho na seleção do sistema construtivo, tendo em vista que o sistema em Concreto e PVC é, em média, cerca de $30 \%$ mais caro que o sistema convencional. Mesmo sem a necessidade do uso de revestimentos no sistema em Concreto e PVC, ainda existe uma variação muito grande do custo inicial da construção. Um fator determinante neste quesito é que os perfis de PVC, não são fabricados no país, o que eleva o seu custo devido ao processo de importação.

Os painéis apesar de estarem registrados no SINAT sob a diretriz n0001 se restringe a construções na região Sudeste do Brasil por conta do alto nível de industrialização necessária para uma implementação que compense economicamente em relação aos sistemas utilizados usualmente.

Já o MSS apesar de promissor se mantém presente apenas em pequenas produções por ser um sistema que pertence a um pequeno grupo empresarial. Com construções que possuem em média 39,4 $\mathrm{m}^{2}$ já atuou no estado brasileiro Espírito Santo na construção de 20 unidades habitacionais voltadas para a classe mais baixa.

Os sistemas utilizando containers e alvenaria de blocos de terra crua se mostram como grandes apostas para o futuro no desenvolvimento de habitações mais baratas e que utilizam materiais próximos as regiões mais afetadas pelo déficit habitacional e que tenha como premissa a redução de resíduos e reciclagem de materiais.

Em relação aos containers a reutilização desse material que por muitas vezes é abandonado pela indústria náutica se torna muito proveitoso tanto do ponto de vista econômico com o baixo preço desses materiais, como do ambiental pela reciclagem promovida por esse empreendimento. Além disso, a possibilidade de expansão das construções, algo que ocorre muito em habitações sociais se torna muito mais fácil com sistemas modulares como os containers.

Os blocos se apresentam como uma alternativa viável para a construção de habitações em regiões rurais do país pela natureza dos materiais que os compõem e pela sua forma de produção. Apesar de se limitar a construções de pequeno porte, a introdução desse sistema para a construção de habitações sociais nessa região poderia contornar os problemas de logística para a utilização de outros materiais mais industrializados. 


\section{CONCLUSÕES}

Observa-se que a literatura oferece uma vasta quantidade de opções para que o mercado brasileiro busque se diversificar no que tange a práticas mais eficazes de construir habitações, o que por si só diminuiria os custos monetários do setor e se faria possível que o grande déficit habitacional do país fosse resolvido de forma plena.

A alvenaria convencional continua sendo o sistema construtivo mais utilizado no país graças a sua prática já estar enraizada no setor nacional. Espera-se que sistemas inovadores como o LSF, LWF, Concreto e PVC, MSS e Painéis de concreto moldado in loco sejam mais praticados no futuro, o que depende diretamente de incentivos governamentais não apenas na pesquisa científica, mas na industrialização do país e da profissionalização da mão de obra disponível.

Outros modelos como alvenaria em blocos de terra crua e habitações em containers apresentam resultados animadores, principalmente, para a implementação de habitações em regiões rurais e costeiras. No entanto, ainda carecem de maior embasamento teórico e de investimentos mais direcionados para que estes se tornem tão viáveis como os outros sistemas discutidos e estabelecidos no mercado brasileiro.

De toda forma, apesar do déficit habitacional no país bater recorde nos últimos anos, em questão tecnológica a comunidade científica nacional apresenta diversas opções para que esta mazela seja solucionada de forma coerente tanto do ponto de vista econômico quanto ambiental.

Por fim, ressaltamos que o maior desafio se encontra na questão política quando analisamos os incentivos e a organização dos planos governamentais de habitação social, mas também no setor da construção civil que mantém um certo conservadorismo pelo anseio da perda de dinheiro ao apostar em novas tecnologias e o possível encarecimento da mão de obra caso estes se especializem.

\section{REFERÊNCIAS}

BRANDÃO, D.. Disposições técnicas e diretrizes para projeto de habitações sociais evolutivas. Ambiente Construído, v.11, n.2, p.73-96, 2011. DOI: https://doi.org/10.1590/S167886212011000200006

BRANDÃO, L.; MELO, K.. Análise de diferentes tipologias de construção em concreto e PVC. In: ENCONTRO NACIONAL DE TECNOLOGIA DO AMBIENTE CONSTRUÍDO, 15. Anais. 2014. p.3437-3445. DOI: http://doi.org/10.17012/entac2014.631

BERNARDES, M.; NILSSON, S. G.; MARTINS, S. M.; ROMANINI, A.. Comparativo Econômico da Aplicação do Sistema Light Steel Framing em Habitação de Interesse Social. Revista de Arquitetura IMED, v.1, n.1, p.31-40, 2012.

CALIL JÚNIOR, C. C.; DIAS, A. A.. Utilização da madeira em construções rurais. Revista Brasileira de Engenharia

Agrícola e Ambiental, v.1, p.71-77, 2000.

CARVALHO, N.; GUIMARÃES, M.; CASTILLO, L..

Desenvolvimento de Alternativas Sustentáveis Para Habitação de Baixa Renda. CONGRESSO BRASILEIRO DE PESQUISA E DESENVOLVIMENTO EM DESIGN. Anais. São Paulo: AEND, 2008.
COSTA, E.; VIEIRA, J.; SANTOS, J.. Estudo comparativo entre o sistema construtivo light steel frame e o sistema de alvenaria convencional em casas populares. CONGRESSO TÉCNICO CIENTÍFICO DA ENGENHARIA E DA AGRONOMIA. Anais. Palmas: UNIP, 2019.

ESPINDOLA, L. D. R.; INO, A.. Inserção e financiamento do sistema Wood Frame no programa habitacional Minha Casa Minha Vida. In: ENCONTRO NACIONAL DE TECNOLOGIA DO AMBIENTE CONSTRUÍDO, 15. Anais. 2014. p.1578-1587. DOI: http://doi.org/10.17012/entac2014.566

FABRO, F.; BULHÕES, R. I.; FORMOSO, T. C.; FIREMAN T. C. M.. Diretrizes para planejar e controlar o processo de montagem de sistemas construtivos pré-fabricados de aço. Ambiente Construído, v.20, n.2, p.505-524, 2020. DOI: http://dx.doi.org/10.1590/s1678-86212020000200412

FARIAS, R.; PASSOS, S. C. I.; LIMA, B. F.; BARBIRATO, M. G.; BARBOZA, R. S. A.; BARBIRATO, C. C. J.; GOMES, C. C. P.. Aplicação de processo de racionalização utilizando blocos de concreto e avaliação de desempenho térmico-estrutural de habitação de interesse social construída em Maceió. In: ENCONTRO NACIONAL DE PESQUISA-PROJETO-PRODUÇÃO EM CONCRETO PRÉ-MOLDADO. Anais. São Carlos, 2005. 
FGV. Fundação Getúlio Vargas. Análise das Necessidades Habitacionais e suas Tendências para os Próximos Dez Anos. Rio de Janeiro: FGV, 2018.

GALVÃO, M. C. B.; RICARTE, I. L. M.. Revisão sistemática da literatura: conceituação, produção e publicação. Logeion: Filosofia da Informação, v.6, n.1, p.57-73, 2019. DOI: https://doi.org/10.21728/logeion.2019v6n1.p57-73

GARCIA, S.; MARTINS, S. M.; ROMANINI, A.; BERNARDES, M. Análise de sistemas construtivos para implementação em habitação de interesse social. In: MOSTRA DE INICIAÇÃO CIENTÍFICA E EXTENSÃO COMUNITÁRIA, 7. Anais. Passo Fundo: IMED, 2013.

GOMES, C. E. M.; VIVAN, L. A.; SICHIERI, E. P.; PALIARI, C. J.. Light Steel Frame: Construção Industrializada a Seco para Habitação Popular - Práticas Sustentáveis. In: ENCONTRO LATINO AMERICANO DE EDIFICAÇÕES E COMUNIDADES SUSTENTÁVEIS. Anais. 2013. p.01-11. DOI: http://dx.doi.org/10.12702/978-85-89478-40-3-a022

GUIMARÃES, M. M.; COSTA, V. S.; GONÇALVES, J. R. M. R.. Vantagens ambientais do sistema construtivo light steel framing no segmento de construção civil. Revista Tecnológica da Universidade Santa Úrsula, v.2, n.1, p.39-54, 2019.

LIBERATTI, A.; TETZLAFF, J.; MOHER, D.. Principais itens para relatar Revisões sistemáticas e Meta-análises: A recomendação PRISMA. Epidemiologia e Serviços de Saúde, v.24, n.2, p.335-342, 2015. DOI: http://doi.org/10.5123/S1679-49742015000200017

MELO, A. B.; BARBOSA, P. N.; LIMA, F. R. M.; SILVA P. E.. Desempenho estrutural de protótipo de alvenaria construída com blocos de terra crua estabilizada. Ambiente Construído, v.11, n.2, p.111-124, 2011.

MENDES, M.; FABRICIO, M.; IMAI, C.. Sistemas Construtivos Inovadores no Contexto do SiNAT: Normativas, Produção e Aplicações de Painéis de Vedação. In: FABRíCIO, M. M.; BRITO, A. C.; VITTORINO, F.. Avaliação de desempenho de tecnologias construtivas inovadoras: conforto ambiental, durabilidade e pós-ocupação. 2017. p.169-194. DOI: http://dx.doi.org/10.26626/978-85-5953-029-

\subsection{C0007.p.169-194}

NOGUEIRA, C. F. B.; SAFFARO, F. A.; GUADANHIM, S. J.. Diretrizes de projeto para a redução de perdas na produção de Habitações de Interesse Social customizadas com painéis pré-fabricados em sistemas de construção a seco. Ambiente Construído, v.18, n.1, p.67-89, 2018. DOI: http://dx.doi.org/10.1590/s1678-86212018000100210

OLIVIERI, H.; BARBOSA, A. C. I.; ROCHA, C. A.; GRANJA, D. A.; FONTANINI, P. S. P.. A utilização de novos sistemas construtivos para a redução no uso de insumos nos canteiros de obras: Light Steel Framing. Ambiente Construído, v.17, n.4, p.45-60, 2017. DOI: http://dx.doi.org/10.1590/s167886212017000400184

RAMOS, J. D. S.; NOIA, A. C.. A Construção de Políticas Públicas em Habitação e o Enfrentamento do Déficit Habitacional no Brasil: uma análise do Programa Minha Casa Minha Vida. Desenvolvimento Em Questão v.14, n.33, p.65105, 2016.

RECK, R. H.; BATAGLIN, F. S.; FORMOSO, C. T.; BARTH, K. B.; DIEPENBRUCK, T.; ISATTO, E. L.. Diretrizes para a definição de lotes de montagem de sistemas pré-fabricados de concreto do tipo Engineer-to-order. Ambiente Construído, Porto Alegre, v.20, n.1, p.105-127, 2020. DOI: http://dx.doi.org/10.1590/s1678-86212020000100365

SALOMÃO, P.; SOARES, A.; LORENTZA, L.; PAULA, L.. Análise comparativa dos sistemas construtivos alvenaria convencional e light steel framing: um estudo de caso em residência uniifamiliar em Teófilo Otoni, MG. Research, Society and Development, v.8, n.5, p.26, 2019. DOI: http://dx.doi.org/10.33448/rsd-v8i9.1268

SOTSEK, N.C.; SANTOS, A. P. L.. Panorama do sistema construtivo light wood frame no Brasil. Ambiente Construído, v.18, n.3, p.309-326, 2018. DOI: http://dx.doi.org/10.1590/s1678-86212018000300283

SOUZA, D. A.; PINHO, G. C. S.. Sistemas construtivos industrializados para habitação social: análise do container como uma nova alternativa. Brazilian Journal of Development, v.5, n.8, p.12413-12430, 2019. DOI: http://doi.org/10.34117/bjdv5n8-085

A CBPC - Companhia Brasileira de Produção Científica (CNPJ: 11.221.422/0001-03) detém os direitos materiais desta publicação. Os direitos referem-se à publicação do trabalho em qualquer parte do mundo, incluindo os direitos às renovações, expansões e disseminações da contribuição, bem como outros direitos subsidiários. Todos os trabalhos publicados eletronicamente poderão posteriormente ser publicados em coletâneas impressas sob coordenação da Sustenere Publishing, da Companhia Brasileira de Produção Científica e seus parceiros autorizados. Os (as) autores (as) preservam os direitos autorais, mas não têm permissão para a publicação da contribuição em outro meio, impresso ou digital, em português ou em tradução. 